\title{
Ultrasound Viewers’'Attribution of Moral Status to Fetal Humans: A Case for Presumptive Rationality
}

\author{
- Heidi M. Giebel -
}

\begin{abstract}
As several studies, along with a book and movie depicting the true story of a former clinic director, have recently brought to the public's attention, fetal ultrasound images dramatically impact some viewers' normative judgments: a small but non-negligible proportion of viewers attribute increased moral status to fetal humans and even form the belief that abortion is impermissible. I consider three types of psychological explanation for a viewer's shift in beliefs: (1) increased bonding or empathy, (2) various forms of cognitive bias, and (3) type of cognitive processing involved. I consider the normative implications of each explanation, arguing that in each case the viewer's judgment is presumptively rational.
\end{abstract} Keywords: ethics, psychology, empathy, bias, abortion, judgment, cognition

Published online: 19 June 2020

\section{Introduction}

Abby Johnson dropped the ultrasound probe and ran, crying, from the procedure room. Despite working for years at the clinic, she'd never assisted with an abortion before. And, despite three pregnancies of her own, two of which she had aborted, she was surprised by the images on the monitor's screen: she'd expected to see something looking more like "tissue" or "cells." Upon seeing that the first-trimester fetal human she helped to abort was, well, human - that it had arms and legs, a heartbeat, etc., along with seemingly purposive movement-Johnson experienced a radical shift in judgment regarding the moral status of embryonic and fetal humans. ${ }^{1}$ She describes her reaction to the experience as follows:

What was in this woman's womb just a moment ago was alive. It wasn't just tissue, just cells. That was a human baby - fighting for life! A battle that was lost in the blink of an eye. What I have told people for years, what I've believed and taught and defended, is a lie. ${ }^{2}$

Heidi M. Giebel

University of St. Thomas

2115 Summit Ave.

St. Paul, MN, 55105, USA

email: hmgiebel@stthomas.edu

${ }^{1}$ For the sake of brevity, henceforth I use "fetal human" to refer to a human being at any stage of prenatal development. While some argue that even the term "human being" is not unambiguously applicable until about two weeks post-fertilization, when cell differentiation is apparent (e.g., Marquis (2007)), any ambiguity in this area does not impact my analysis: the ultrasound images under discussion depict fetal humans well beyond the two-week mark.

${ }^{2}$ Johnson (2011): 7. See also the 2019 movie Unplanned, which depicts the same story. 
Johnson came to view fetal humans as persons with full moral status and abortion as morally impermissible; she quit her job at the clinic and ultimately became an anti-abortion activist.

Although Johnson's story is considerably more dramatic than most, her reaction to viewing fetal ultrasound images is not unique-even among those who, like Johnson, would seem to have a vested interest in retaining the belief that fetal humans are due minimal moral consideration. For example, even among women about to procure abortions, voluntarily viewing images from a pre-procedure ultrasound seems to lead a small but non-negligible percentage to change their minds and continue their pregnancies after all. ${ }^{3}$ And some pregnancy help centers, which report that around 30\% of their clients are planning or seriously considering abortion, have found that after exposure to ultrasound images and further information regarding prenatal development only two to $15 \%$ choose to abort. ${ }^{4}$ Further, as a recent Slate article and a more classic essay by feminist writer Naomi Wolf have noted, the assumption of many anti-abortion groups - and of their pro-abortion opponents - is that viewing images of fetal humans will persuade observers to adopt anti-abortion positions. ${ }^{5}$ In fact, some pregnancy care centers have been accused of using ultrasound images manipulatively in an effort to persuade women to continue with their pregnancies. ${ }^{6}$

How should we understand the changes in ethical beliefs taking place when ultrasound viewers abandon the belief that fetal humans are due minimal moral consideration and instead come to the judgment that fetal humans are morally comparable to you or me?

\footnotetext{
${ }^{3}$ Gatter, Kimport, Foster et al. (2014). In this study of over 15,000 seeking abortions at a Los Angeles clinic, among women who had reported medium or low certainty (as opposed to high certainty) about their decision to abort, over three times as many of those viewing the pre-abortion ultrasound images chose to forego the abortion and continue their pregnancies compared with those who did not view the images (4.8\% versus $1.3 \%$ ). (Among women who reported high certainty, viewing the ultrasound images did not make a statistically significant impact on their decisions.) Upadhyay et al. (2017) found similar results: Among over 5,000 women seeking abortions at a Wisconsin clinic, 8.7\% chose to continue their pregnancies prior to a 2013 mandatory ultrasound law, compared to $11.2 \%$ post-law. Researchers found this statistically significant effect to be impacted by gestational age and the mother's financial situation; selective qualitative follow-up interviews suggested decision certainty was also a factor.

${ }^{4}$ South Dakota Legislature (2005): 19-20, 38. This greater impact of ultrasounds conducted in pregnancy help centers as opposed to abortion clinics likely reflects lower decision certainty among women seeking their services. By contrast, during the time period of the study 814 of the 819 women seeking abortion at South Dakota's only abortion clinic received no information regarding their fetuses other than gestational age; almost all went through with the abortion. (One could of course question the objectivity of reports from pregnancy help centers - or from abortion clinics. But since these types of facilities are in a unique position to access the relevant data, some degree of reliance on their reports seems unavoidable. One work-around might be to conduct a study of reactions of non-pregnant viewers to ultrasound images. Of course, any such study, while affording more objectivity in data collection, would have its own limitations, including an inherent selection bias insofar as its participants would have to be willing to view such images.)

${ }_{5}^{5}$ Waldman (2014); Wolf (1995). As Sanger (2008) argues, the very point of laws mandating that pre-abortive women be offered the opportunity to view their ultrasound scans seems to be the hope that they will change their minds.

${ }^{6}$ For example, John Oliver, in the April 8, 2018 episode of his HBO television show "Last Week Tonight," played a recording (allegedly) of a pregnancy care center staff member saying, "She'll stay on that [ultrasound examination] table until she decides she wants the baby."
} 
As rational responses to additional information or empathic over-arousal? The shedding of old biases or the acquisition of new ones? And does a psychological explanation - even assuming we can be sufficiently confident of its accuracy - have any bearing on the truth of the ethical claims under discussion or the rationality of those who endorse such claims?

Although there are likely hundreds of possible (partial) psychological explanations for the effect of ultrasound images of fetal humans on some viewers' judgments regarding their moral status and the ethical permissibility of abortion, for the sake of brevity we'll focus on what seem the three most obvious types of explanation; at least in some variations, such explanations can be complementary rather than competing. First, viewing images of fetal humans, even as early as five to six weeks post-fertilization, may increase empathy: Seeing fetal humans' faces, limbs, etc. may lead viewers to perceive them as "more human" than previously thought - and thus more natural objects of empathy and possible attachment. Second, the effect of the images on viewers' ethical judgments may be mediated by (or perhaps dispel) various cognitive and empathic biases. For example, a third-party observer who previously empathized only with the pregnant woman (as more similar to himself or as an in-group member) may come to develop a competing loyalty to the fetal human she is carrying; or perhaps the concreteness of the images could trigger here-and-now thinking that favors the immediate interest of the fetal human in continuing to exist above the woman's competing, less-immediate concerns. Third, the ultrasound may provide the viewer with new information, such that the attribution of increased moral status to the fetal human is an instance of ordinary belief formation or revision - either via automatic, intuitive processing or via explicit inference. In the remainder of this essay we'll analyze these three sets of explanations in more depth, exploring each individually as well as areas of overlap and tension among them. We'll also consider the normative implications of each explanation, including the presumptive rationality of the viewers' judgments.

\section{Empathy and Bonding}

The first obvious explanation for a shift in judgment regarding fetal humans among those viewing ultrasound images is increased empathy and (in the case of expectant parents) bonding or attachment. As several studies of responses to routine prenatal ultrasound examinations indicate, expectant parents tend to report "personification and attachment to 'their baby.'"7 For example, one expectant mother, "Barbara," ${ }^{8}$ reflected:

The most important [aspect of the ultrasound scan] is to create a bond between the father, mother and baby. Imagine seeing the head, four limbs and a beating heart, and at the same time realizing that this is ours! ${ }^{9}$

\footnotetext{
7 Øyen, Aune (2016): 12. The authors cite several other studies with similar findings. Of course, people other than the parents would not necessarily develop a similar attachment to the fetal humans. But other viewers might well "personify" them, in the literal sense of attributing to them the metaphysical and moral status of persons, as Abby Johnson did after assisting with an ultrasound-guided abortion.

${ }^{8}$ With the exception of Abby Johnson, the women quoted in this essay are not identified by name;

I've assigned pseudonyms for ease of reference.

9 Øyen, Aune (2016): 10.
} 
Another, "Clotilde," said:

When you see that. . . there is an individual who lives its own life, who becomes a person of its own, and I think this is easier to imagine when you have seen it. I have become much more protective. . . and I didn't feel that at all before the ultrasound. Maybe you feel more like a mother. ${ }^{10}$

And an expectant father, "Steve," remarked:

Up until then it was just a sort of vague blobby thing that was going to happen seven months away.... Since then it has felt real, it has felt as though there's a human being. ${ }^{11}$

Similarly, another study found that a first-trimester ultrasound scan was associated with a modest but significant increase in second-trimester maternal attachment-even compared with expectant mothers who had viewed a more recent second-trimester scan. ${ }^{12}$ Third-trimester ultrasound scans have also been found to increase maternal bonding the clearer the image, the stronger the effect. ${ }^{13}$

In one study, women undergoing routine ultrasound examinations even brought up their increased reluctance to pursue abortion:

Dora: I feel that it is human. It belongs to me. I couldn't have an abortion now. ${ }^{14}$

Elsa: I am going all the way with the baby. I believe it is human. ${ }^{15}$

And even among women whose ultrasound images revealed serious fetal abnormalities leading to miscarriage or abortion, the most common theme researchers found in interviews one to two months after the pregnancy ended was that the images made the fetal human seem more "real," "living," or "human" - which, in some cases, made the loss more difficult. Some of the women described their experiences as follows:

Francine: We saw it move its little arms and legs; we saw a face ... I had imagined it, but when I saw ... it's harder to say to myself it's just a miscarriage. ${ }^{16}$

Giselle: I actually lost a baby instead of a fetus, and I think the sonogram has a lot to do with that. ... It made me feel like I was losing a person instead of a pregnancy. ${ }^{17}$

\footnotetext{
${ }^{10}$ Dykes, Stjernqvist (2001): 98; see also Milne, Rich (1981).

${ }^{11}$ Draper (2002): 780. (I deviate from alphabetical order in my pseudonyms only because the authors of this study named their participants.)

12 Öhman, Waldenström (2010).

${ }^{13}$ de Jong-Pleij, Ribbert, Pistorius et al. (2013).

${ }^{14}$ Fletcher, Evans (1983): 392.

15 Ibidem.

${ }^{16}$ Black (1992): 48.

17 Ibidem: 51.
} 
Harriet (who chose abortion): To tell you the truth, I flashed on [the ultrasound image], thinking about terminating it. I kept thinking about that's what it is, that's what it looks like, but-my baby. ${ }^{18}$

Of course, it is not just pregnant women and their partners who can have strong responses to ultrasound images. For those not experiencing maternal or paternal bonding, empathy seems a natural explanation of this phenomenon: Coming to perceive the fetal human as "more real" or as a baby may encourage viewers to identify with the inferred interests, needs, and even feelings of the fetal human, leading to a "vicarious affective response" involving "feelings that are more congruent with another's situation than with [one's] own situation," 19 just as both children and adults mirror infants' emotional responses. ${ }^{20}$ And if abortion is an imminent reality or likelihood in the case of a particular fetal human (or even if that possibility is imagined), the viewer may experience empathic distress: Indeed, Abby Johnson's strong negative reaction to the ultrasound images she viewed could quite reasonably be described as profound empathic distress.

Empathy is generally considered a good quality to increase: an obvious example of what psychologists call a "prosocial emotion" that tends toward benefitting others. When an observer sees someone in "discomfort, pain, danger, or some other type of distress" and has feelings corresponding to that person's situation, s/he experiences empathic distress, which not only (a) is positively correlated with helping, but (b) precedes and contributes to the helping behavior and (c) is relieved when the observer succeeds in helping. Finally, empathy contributes to decreased aggression and manipulation - additional prosocial benefits. ${ }^{21}$

Although empathy is generally a good, prosocial response to the (potential) suffering of others, it does have its downsides. First and most obviously, empathic distress is unpleasant - and if the costs of alleviating our distress strike us as too high, many of us would rather avoid empathizing in the first place..$^{22}$ The desire not to empathize (and not to bond) with the fetal human may partly explain why, in the study regarding the effect of ultrasound viewing on women's decisions to go through with planned abortions, $57.5 \%$ of the women studied elected not to view the images, ${ }^{23}$ and why some women losing fetal humans to miscarriage or abortion after abnormal screening results regretted viewing their ultrasound images. ${ }^{24}$

Can a judgment or action based on empathy be rational? ${ }^{25}$ The pathos root (referring to pity or sorrow) of the word "empathy" may seem to suggest not - that an empa-

18 Ibidem: 49.

19 Hoffman (2002): 29-30.

20 Ruffman, Then, Cheng et al. (2019).

${ }^{21}$ Hoffman (2002): 30-36; see also chap. 6. For additional analysis, see Giebel (2020), chap. 18.

22 See, e.g., Shaw, Batson, Todd (1994); Batson (2011): 191-193.

${ }^{23}$ Gatter, Kimport, Foster et al. (2014): table 1.

24 Black (1992): 49-50. Perhaps it even explains the strong reactions people on both sides of the abortion debate often have to photos of aborted fetal humans: See, e.g., Wolf (1995).

${ }^{25}$ Here and throughout, by "rational" I mean something like "not irrational" or "not epistemically irresponsible" - I don't mean to indicate that the agents, judgments, or actions fully conformed to standards of economic rationality or logical deduction. Since this short article is not the place to develop and defend a full account of rationality, for present purposes we'll rely on commonsense applications and paradigmatic cases of (ir)rationality, such as the rationality of taking the steps necessary to achieve an important goal and the irrationality of doing what obviously thwarts one's own ends, acknowledging that further analysis would be required for difficult cases. 
thy-based reaction is by nature purely emotional and even irrational. But of course we humans are more complex than that: Our reason can guide our emotional responses - a key aspect, as philosophers since at least the time of Plato and Aristotle have pointed out, of our development of virtue or vice. ${ }^{26}$ And early Confucian philosopher Mencius famously seemed to link empathic distress (a "feeling of alarm and compassion" upon seeing a child in danger) to cultivation of the key virtue of benevolence. ${ }^{27}$ More recently, Christian Miller, a psychologically-informed philosopher, has explored the relationship between empathy and virtuous compassion, arguing that empathy increases helping behavior by eliciting genuinely altruistic motivations. ${ }^{28}$ "And philosopher Michael Slote has worked to base an entire ethical theory on empathy..$^{29}$ So it seems that empathy has an important role to play, alongside and in cooperation with reason, in developing and exercising ethical virtue.

Psychologists, too, have been optimistic about empathy's role in virtue development-especially when mediated by cognition. According to Hoffman:

Cognitive development (self-other differentiation, language mediation, role-taking, causal attribution) enables simple empathic distress to be transformed into increasingly sophisticated motives to consider the welfare of others, taking their life condition as well as their immediate feelings into account. ... Empathy's amenity to cognitive influence is also important for another reason: It gives a potentially significant role to socialization and moral education, which may counteract empathic morality's limitations and magnify its capabilities. ${ }^{30}$

So as long as empathy remains within rational bounds, judgments and actions that it influences also can be rational: at the very least, in the sense that such judgments and actions are not irrational. Further, it can help us to grow in virtues like benevolence, generosity, and kindness - and, if Aristotelian and Confucian philosophers are correct, growing in those virtues can in turn help us to form more accurate ethical judgments.

These philosophical and psychological assessments suggest that our empathic responses, like our sense impressions, are generally trustworthy. In the absence of strong evidence to the contrary, then, the empathic responses of Abby Johnson and the other women quoted in this article to fetal ultrasound images, leading to increased moral

\footnotetext{
${ }^{26}$ See, e.g., Plato (1992): bk. IV; Aristotle (1999): bk. II.

${ }^{27}$ Mencius (2004): 2A6. Of course, David Hume also associated benevolence with a sympathetic (today we might say "empathic") emotional response - but he thought reason was largely the passions' slave rather than their guide. See Hume (2011): II.3.3.

${ }^{28}$ Miller (2013): 108-119, as Miller defines it, “A person's ultimate desire is altruistic just in case: (i) It concerns what she things benefits (at least) one person who is not herself. (ii) The desire cannot be satisfied unless someone other than herself would be benefitted in her eyes, and benefitted in such a way that is independent of what would subsequently benefit her" (2013): 113. As I note below, Miller also acknowledges empathy's ethical limitations.

${ }^{29}$ Slote (2007). Although analysis of Slote's work is beyond my scope here, for an interesting critique see Hourdequin (2015); for a discussion of his empathy-based analysis of abortion in particular, along with analysis of the impact of medical and social norms on empathy with fetal humans, see Mills (2018).

${ }^{30}$ Hoffman (2002): 287.
} 
consideration of the fetal humans viewed, should be presumed rational and possibly even conducive to ethical development. In fact, even Waldman, the pro-abortion author of the Slate article referenced earlier, grants the rationality of these women, even while apparently assuming their response is primarily emotional:

Women who voluntarily look at ultrasounds and then decide against abortion are acting as rationally as the ones who decide to go through with it. We all make choices along a variety of axes: the financial axis; the relationship-status axis; the personal goals and dreams axis; the ethical axis; and, yes, the emotional axis. Expecting women to ignore any one scrap of data (as if they are not capable of weighing it, carefully, alongside the others) is underestimating women. ${ }^{31}$

When it does not remain within its bounds, however, overreliance on empathy can help facilitate irrationality and even vice. For example, empathy can be overaroused, causing the empathizing agent to become the "victim" of another's distress - and to focus on eliminating her own distress rather than that of the one actually suffering. And although there may be many ways to reduce empathic overarousal (e.g., physical or mental distancing, meditation, talk therapy), its possibility serves as a good reminder to keep other tools, such as normative principles of justice, in our ethical toolkit.

Another limitation of empathy is that it is susceptible to bias: We tend to empathize more strongly with, e.g., those we know, those who are immediately present, and those who are more similar to us, which can lead us to disregard the more pressing needs of others. Indeed, psychologist Paul Bloom has recently argued that this limitation of empathy is so serious that it tends to impact our ethical judgment negatively rather than positively. ${ }^{32}$ We will next examine several types of bias that may be implicated in - or mitigated by - reactions to fetal images.

\section{Bias}

As with psychological explanations more generally, accounts of cognitive bias are myriad: Depending upon which researcher you ask, we may be susceptible to dozens or even hundreds of different biases. So once again we'll limit our discussion to a few of the most obvious categories, noting, when applicable, how they relate to our previous analysis of empathy and bonding. ${ }^{33}$

${ }^{31}$ Waldman (2014).

32 Bloom (2016), esp. chap. 3 and 5; cf. Miller (2013): 126-29. Even Bloom (2016: chap. 4), however, acknowledges that it is fitting to care more - and perhaps even empathize more - with family members than with strangers. And of course the debate about abortion concerns, among other things, whether the fetal human should be counted as a family member. To some extent, as Bloom (2016: chap. 1) acknowledges, his negative assessment of empathy, in contrast to other authors' positive assessments, is partly a function of the varying definitions among authors: e.g., Hoffman (2002) defines it as a vicarious affective response to another's situation, Slote (2007) defines it as sharing another's emotions, and others even use it roughly synonymously with "compassion" or "caring." For detailed analysis of these varied uses, see Batson (2009). ${ }^{33}$ Cognitive biases are distinct from any bias in the presentation or framing of the information itself: Although a biased presentation obviously can impact the cognitive processing and moral judgments of its recipients, the way in which it does so is beyond the scope of this essay. 
Self-serving bias. Perhaps most obviously, our thinking tends toward bias in favor of ourselves: We have a natural tendency to interpret our own actions, motives, and traits more favorably than those of others; and we try to justify or rationalize actions and judgments that serve our own interest. We also have a strong confirmation bias: a tendency to focus upon and even seek out information that confirms our preexisting beliefs. We see this sort of bias every day in the form of people's chosen television news sources and social media feeds. One of the most interesting aspects of abrupt changes in belief, such as those of Abby Johnson and of the women who chose to forgo abortion upon viewing pre-procedure ultrasound images, is that they appear to flout these strong human tendencies: to eschew a natural inclination to tell themselves that their past judgments and decisions and their current courses of action are morally unproblematic, and even to change course in ways that would seem obviously counter to their own personal or financial interest.

A plausible explanation of this change in belief and action, then, must be powerful enough to account for the strength of the biases that were set aside. If the new information itself doesn't fully explain a particular shift in judgment and action, we might suspect that a countervailing bias is at play; we'll consider two additional common types of bias.

Familiarity bias. In addition to favoring ourselves in our judgments, we tend to favor those familiar to us: our family members and friends, members of groups with which we identify, and people similar to us in various ways. As Hoffman shows, familiarity bias is empathic as well as cognitive: It impacts the degree to which we empathize with - and respond to-another's distress. ${ }^{34}$ For example, college students are more willing to help strangers who are fellow students from the same university than those from another university in the same town. ${ }^{35}$ In the case of third parties viewing ultrasound images, perhaps the images provide sufficient familiarity (in the form of either similarity or group co-membership) to tip the scales of judgment in favor of the fetal human - or at least less strongly in favor of the more-familiar pregnant woman's competing interests. In the case of a change in judgment on the part of the woman herself, she might even come to see the fetal human as a family member. But these explanations, like those regarding the related phenomenon of self-serving bias, seem more easily interpreted primarily as instances of overcoming preexisting biases than as simply acquiring new ones - after all, the pregnant woman and her interests remain more familiar than those of the fetal human despite any increase in its familiarity. Such a positive interpretation seems less natural in the case of the final type of bias we'll consider.

Here-and-now bias. In addition to familiarity bias, one other cognitive bias dramatically impacts empathy: here-and-now bias, especially in its more specific instantiation, the identifiable victim effect, or the tendency to favor "victims who are present in the immediate situation." ${ }^{36}$ For example, philosopher Peter Unger used a variety of hypothetical cases to show that we (irrationally, he argued) prefer to rescue one immediate-

\footnotetext{
${ }^{34}$ Hoffman (2002: chap. 8); cf. Bloom (2016).

${ }^{35}$ Graziano, Habashi (2015): 239-240; see Coke, Batson, McDavis (1978). For an interesting study showing the tendency, even among infants, to prefer those who share trivial similarities, see Mahajan, Wynn (2012).

${ }^{36}$ Hoffman (2002): 14; cf. chap. 8.
} 
ly-present victim rather than use the same resources to save many distant victims via donation to organizations like Oxfam.$^{37}$ Although the woman is obviously present during an ultrasound scan of the fetal human inside of her, she is not, so to speak, the star of the show - the scan focuses almost exclusively on the fetus. So a viewer who considers the fetal human to be subject to possible danger or distress - a potential victim - might be prone to a cognitive and empathic bias favoring the rescue of the fetal human above sparing the woman (or anyone else) similarly significant distress. Such an explanation seems quite plausible in the case of imminent abortion: There is an obvious - even mortal-danger attributable to the fetal human. The seriousness of such danger, however, may cast into doubt our common usage of the term "bias."

Unlike empathy, bias is generally taken to be a negative aspect of a judgment, action, or attribution: The term "bias" normally refers to a disproportionate, unfair weighting of the relevant considerations. But psychology, as an empirical discipline, can show only that we weight such considerations differently-it does not directly address whether such differences are unfair. We will need further conceptual analysis to make that determination. So the ethical question really is not whether a judgment is "biased," at least in the empirical sense of the term, but: Does a judgment favoring oneself, familiar others, or the here-and-now transgress the norms of rationality or justice in this situation? ${ }^{38}$ For example, while it may be perfectly reasonable to favor ourselves and our families when distributing our own paychecks or the contents of our closets and refrigerators, it is clearly unjust to do so when distributing others' property or public goods. In fact, Hoffman ends his discussion of empathy and moral education by emphasizing that we need not eliminate empathic bias altogether: As the Confucians emphasized, it can be acceptable and even virtuous to give more of our own time and resources to those closest to us - again, as long as we don't overstep the limits of justice.

As we saw, in the case of a shift in judgment upon viewing live ultrasound images, the agents seemed more plausibly described as eschewing our usual self-serving or familiarity biases in favor of affording more consideration to the other or the less-familiar. Was it irrational or unjust not to favor the interests of oneself or the more familiar other over the fetal human's immediate interest in remaining alive? If the agent reasonably believed the fetal human's moral status to be equal or comparable to that of its mother, then it was rational and just to give increased weight to its interest in continuing to live; if not, then doing so seems irrational.

Similarly, favoring here-and-now considerations is not necessarily irrational or unethical: In an emergency, for example, the immediate situation appropriately takes temporary precedence. And if the viewing agent reasonably believed the fetal human to have significant moral status, then an imminent possibility of abortion could reasonably be considered an emergency; if not, then a bias toward its here-and-now interests again seems irrational.

\footnotetext{
${ }^{37}$ Unger (1996).

${ }^{38}$ Although my own justice-related philosophical commitments are predominantly Aristotelian, for purposes of this article it is not necessary to explicate or defend a specific account of justice. My aim is to provide a bigger-picture analysis compatible with any number of (reasonable) accounts, leaving it to the reader to apply his or her own account, if desired, to come to more specific conclusions about the cases and actions discussed.
} 
Note, however, that even if Johnson and the pregnant women quoted in this essay did judge irrationally in not continuing to discount the interests of the fetal humans they viewed, their judgments and actions were not unjust: Johnson was not bound by justice to retain her job at the abortion clinic, nor were the pregnant women bound to abort. Thus, any accusation of injustice on the part of these viewers is unfounded, and any attribution of irrationality assumes that the viewer's inferences regarding the moral status of the fetal human are unreasonable. We will analyze the rationality of such inferences next.

\section{Cognitive Processing, Fast and Slow}

Regardless of whether a judgment favoring someone with here-and-now distress is always accurately described as a bias, here-and-now thinking is clearly different from the slower, less-intuitive style of thinking we might use for data analysis or logical proofs. This dual-process account of cognition, as described by Nobel laureate Daniel Kahneman in Thinking, Fast and Slow and applied to ethical judgment, ${ }^{39}$ may usefully explain the reactions of some viewers of fetal ultrasound images.

On the "fast" side of human cognition, fetal humans' characteristically human appearance may encourage an automatic, intuitive judgment that they are due moral consideration.

Further, a fascinating set of recent studies suggests that the visual (as opposed to verbal) nature of such images may itself encourage just this sort of intuitive thinking. Psychologists Elinor Amit and Joshua Greene proposed that because of its inherently concrete nature, visual imagery pertaining to moral decision-making would tend to favor consideration of concrete actions and their immediate impact, while verbal descriptions would tend to favor more abstract ends to be achieved. They found that people with more visual cognitive styles generally tend to judge sacrificing one person to save others as less morally acceptable than do those with more verbal styles - and that those more vividly visualizing the plight of the one to be sacrificed are more likely to judge the sacrifice morally unacceptable. ${ }^{40}$

A similar effect could quite plausibly be found with regard to fetal ultrasound images. Seeing a vivid image of the fetal human in real time may lead viewers toward an intuitive judgment that it would not be acceptable to sacrifice its interests in favor of the interests of others. This explanation seems especially likely in a case like that of Abby Johnson, whose shift in judgment occurred upon seeing via ultrasound the actual demise of a fetal human.

Like empathy (and sensation), while "fast," intuitive thinking is an ordinary human phenomenon and generally serves us well, it can occasionally lead us astray, especially when overused..$^{41}$ Unfamiliar or difficult situations tend to call for more reli-

\footnotetext{
${ }^{39}$ See Kahneman (2011), which provides an accessible summary of his work in dual-process cognition. For an interesting take on its application to moral judgment, see Haidt (2012). For recent developments and critiques of dual-process theory, see, e.g., Evans, Stanovich (2013); De Neys, Pennycook (2019); De Neys (2017).

${ }^{40}$ Amit, Greene (2012): 862, 866.

${ }^{41}$ See Kahneman (2011), esp. part II.
} 
ance on our other main type of cognitive process: the explicit and deliberate weighing of information; we'll next consider that process and its implications.

Perhaps the most obvious explanation of Abby's and others' attribution of moral status to fetal humans is that ultrasound images convey previously-unknown (or at least unprocessed) information - reasons or evidence - forming the basis of the new judgment. Thus the viewers may be making ordinary, presumptively rational inferences of the sort we routinely make in response to new information in other contexts - for example, our formation or alteration of beliefs about today's weather upon glancing out the window. ${ }^{42}$ Such reason-based inferences, even when made quite quickly, fall into the "slow," deliberate category of cognitive processing insofar as they are conscious and explicit.

What might the new or newly-processed information be in this case? As the quotations in section I suggest, these ultrasound viewers learned that fetal humans resemble more mature human beings: Viewers emphasized seeing faces, arms, legs, and purposive movement-even "fighting for life." As one pregnant woman, "Ivy," summarized her experience:

We were slightly ambivalent before [the ultrasound scan] ... I didn't plan on getting pregnant. ... But actually seeing [the images] made a very big difference; it was no question after that. ... It's suddenly having a conception of what emerging life really is. ${ }^{43}$

In at least some of these cases, then, there appeared to be a conscious inference from something like "this appears to be a living human being" to "this being's moral status is similar to that of other living human beings." Further, as the authors studying the effects of pre-abortion ultrasounds noted, the ultrasound examinations provided information additional to the image itself: particularly gestational age - and increased gestational age was associated with increased likelihood of continuing the pregnancy. ${ }^{44}$ In such cases, there was very likely an explicit inference from the fetal human's age or level of development to its moral status, or at least to the undesirability of aborting it.

Explicit, reason-based inferences are paradigmatic of rational thought, so the burden of proof falls upon one who would deny the inference's rationality. (Note that such denial is a different-much stronger-claim than the denial of the truth of the agent's conclusion.) In the cases we've examined the inferences appear to be from information like the fetal human's shape (four limbs, face, beating heart) and movement to the conclusion that the fetal human (even, in some cases, the fetal human the viewer chose to abort) was "a person," "a living human," "a baby," or even "my baby" or "our baby." While such inferences may be subject to doubt (e.g., if one encounters arguments for contrary conclusions), they don't seem at all irrational: In fact, they are quite analogous to the automatic judgments we form every day upon encountering moving, human-shaped beings.

\footnotetext{
${ }^{42}$ Since the philosophical and psychological literature on the topic of rational belief formation is vast and this short essay clearly is not the place to develop or defend a full account, this commonsense account and example must suffice for present purposes.

${ }^{43}$ Black (1992): 49.

${ }^{44}$ Gatter, Kimport, Foster et al. (2014): 86.
} 


\section{Conclusion}

In this essay we have considered several possible explanations for the onset of a belief in the moral significance of fetal humans and/or the impermissibility of elective abortion upon viewing live fetal ultrasound images. Such a shift in normative judgment may be the result of (a) an empathic response to the fetal human and its perceived (potential) danger or distress, (b) the exercise or elimination of a cognitive bias, or (c) ordinary cognitive processing of new information conveyed in the images. Under each of these explanations the viewer's judgment is presumptively rational. As psychologist Martin Hoffman and philosophers like Mencius have argued, our empathic responses are generally reliable and conducive to developing virtues such as justice and benevolence. The viewers' revised judgments likely indicate overcoming of self-serving or familiarity bias; and, at least if the viewers reasonably believe the fetal humans they view to have significant moral status, any here-and-now bias (in the empirical, non-normative sense of the term "bias") displayed is neither irrational nor unfair. And, whether the viewers form their new judgments via "fast," intuitive cognitive processing or "slow," explicit inference, their exercise of these ordinary cognitive processes is presumptively rational. On that basis, then, and in closing, I propose the following normative conclusion: In the absence of overwhelming evidence to the contrary in a particular case, we should give agents who change their normative stance in cases like these the benefit of the doubtboth as to their rationality and as to their motivation and character.

\section{References}

Amit E., Greene J. (2012), “You See, the Ends Don't Justify the Means: Visual Imagery and Moral Judgment," Psychological Science 23 (8): 861-868.

Aristotle (1999), Nicomachean Ethics, trans. T. Irwin, Hackett, Indianapolis.

Giebel H. (2020), Ethical Excellence: Philosophers, Psychologists, and Real-Life Exemplars Show Us How to Achieve It, CUA Press, Washington (DC).

Batson C.D. (2009), "These Things Called Empathy: Eight Related but Distinct Phenomena," [in:] Social Neuroscience. The Social Neuroscience of Empathy, J. Decety, W. Ickes (eds.), The MIT Press, Cambridge (MA): 3-15.

Batson C.D. (2011), Altruism in Humans, Oxford University Press, New York.

Black R.B. (1992), "Seeing the Baby: The Impact of Ultrasound Technology," Journal of Genetic Counseling 1 (1): 45-54.

Bloom P. (2016), Against Empathy: The Case for Rational Compassion, HarperCollins, New York.

Coke J.S., Batson C.D., McDavis K. (1978), “Empathic Mediation of Helping: A Two-Stage Model," Journal of Personality and Social Psychology 36 (7): 752-766.

De Neys W. (ed.) (2017), Dual-Process Theory 2.0, Routledge, Oxon/New York.

De Neys W., Pennycook G. (2019), “Logic, Fast and Slow: Advances in Dual-Process Theorizing," Current Directions in Psychological Science 28 (5): 503-509.

Draper J. (2002), "It Was a Real Good Show': The Ultrasound Scan, Fathers, and the Power of Visual Knowledge," Sociology of Health and Illness 24 (6): 771-795.

Dykes K., Stjernqvist K. (2001), “The Importance of Ultrasound to First-Time Mothers' Thoughts about Their Unborn Child," Journal of Reproductive and Infant Psychology 19 (2): 95-104. 
Evans J.S.B.T., Stanovich K.E. (2013), “Dual-Process Theories of Higher Cognition: Advancing the Debate," Perspectives on Psychological Science 8 (3): 223-241.

Fletcher J.C., Evans M.I. (1983), "Maternal Bonding in Early Fetal Ultrasound Examinations," New England Journal of Medicine 308: 392-393.

Gatter M., Kimport K., Foster D.G. et al. (2014), “Relationship Between Ultrasound Viewing and Proceeding to Abortion," Obstetrics and Gynecology 123 (1): 81-87.

Gettier E. (1963), “Is Knowledge Justified True Belief?,” Analysis 23 (6): 121-123.

Graziano W.G., Habashi M.M. (2015), "Searching for the Prosocial Personality," [in:] The Oxford Handbook of Prosocial Behavior, D.A. Schroeder, W.G. Graziano (eds.), Oxford University Press, New York: 231-256.

Haidt J. (2012), The Righteous Mind: Why Good People are Divided by Politics and Religion, Vintage Books, New York.

Hoffman M.L. (2002), Empathy and Moral Development: Implications for Caring and Justice, Cambridge University Press, Cambridge.

Hourdequin M. (2015), "The Limits of Empathy," [in:] Virtue Ethics and Confucianism, S.C. Angle, M. Slote (eds.), Routledge, New York: 209-218.

Hume D. (2011), A Treatise of Human Nature. Volume 1: Texts, D. Norton, M. Norton (eds.), [in:] D. Hume, Clarendon Hume Edition Series, Clarendon, Oxford.

Johnson A. (2011), Unplanned: The Dramatic True Story of a Former Planned Parenthood Leader's Eye-Opening Journey across the Life Line, Tyndale House, New York.

de Jong-Pleij E.A.P., Ribbert L.S.M., Pistorius L.R. et al. (2013), “Three-Dimensional Ultrasound and Maternal Bonding, a Third Trimester Study and a Review," Prenatal Diagnosis 33 (1): 81-88.

Kahneman D. (2011), Thinking, Fast and Slow, Farrar, Strauss and Giroux, New York.

Mahajan N., Wynn K. (2012), “Origins of 'Us' versus 'Them': Prelinguistic Infants Prefer Similar Others," Cognition 124 (2): 227-233.

Marquis D. (2007), “The Moral-Principle Objection to Human Embryonic Stem Cell Research," Metaphilosophy 38 (2-3): 190-206.

Mencius [Mengzi] (2004), Mengzi, trans. B. Van Norden, Hackett, Indianapolis.

Miller C. (2013), Moral Character: An Empirical Theory, Oxford University Press, Oxford.

Mills C. (2018), "Seeing, Feeling, Doing: Mandatory Ultrasound Laws, Empathy, and Abortion," Journal of Practical Ethics 6 (2): 1-31.

Milne L.S., Rich O.J. (1981), “Cognitive and Affective Aspects of the Responses of Pregnant Women to Sonography," Maternal-Child Nursing Journal 10 (1): 15-39.

Öhman S.G., Waldenström U. (2010), "Effect of First-Trimester Ultrasound Screening for Down Syndrome on Maternal-Fetal Attachment - A Randomized Controlled Trial," Sexual and Reproductive Healthcare 1: 85-90.

Øyen L., Aune I. (2016), “Viewing the Unborn Child - Pregnant Women's Expectations, Attitudes, and Experiences Regarding Fetal Ultrasound Examination," Sexual and Reproductive Healthcare 7: 8-13.

Plato (1992), Republic, trans. B. Jowett, Hackett, Indianapolis.

Ruffman T., Then R., Cheng C. et al. (2019), “Lifespan Differences in Emotional Contagion While Watching Emotion-Eliciting Videos," PLoS ONE 14 (1): e0209253.

Sanger C. (2008), "Seeing and Believing: Mandatory Ultrasound and the Path to a Protected Choice," UCLA Law Review 56 (2): 351-408.

Shaw L.L., Batson C.D., Todd R.M. (1994), “Empathy Avoidance: Forestalling Feeling for Another in Order to Escape the Motivational Consequences," Journal of Personality and Social Psychology 67 (5): 879-887. 
Slote M. (2007), The Ethics of Care and Empathy, Routledge, New York.

South Dakota [USA] Legislature (2005), "Report of the South Dakota Task Force to Study Abortion," URL = http://rewire.news/wp-content/uploads/2014/10/South-Dakota-Abortion-Task-Force-Report.pdf [Accessed 08.06.2020].

Unger P. (2006), Living High and Letting Die: Our Illusion of Innocence, Oxford University Press, Oxford.

Waldman K. (2014), “Does Looking at an Ultrasound Before Abortion Change Women's Minds?," Slate, URL = https:/ / slate.com/human-interest/2014/01/ultrasound-viewing-before-an-abortion-a-new-study-finds-that-for-a-small-percentage-of-womensonograms-change-minds.html [Accessed 08.06.2020].

Wolf N. (1995), "Our Bodies, Our Souls: Rethinking Pro-Choice Rhetoric," New Republic 213 (16): 26, 28-29, 32-35. 